\title{
Mucopolysaccharide in the blood of a patient with neuroblastoma
}

P. M. G. BROUGHTON, J. R. W. DYKES, SHIRLEY HOLT, J. W. RIDLEY, AND A. E. STEEL

From the Departments of Chemical Pathology and Pathology, University of Leeds, and the Department of Biochemistry, Killingbeck Hospital, Leeds

SYNOPSIS In a case of neuroblastoma the presence of an abnormal blood constituent was suspected from the raised erythrocyte sedimentation rate, sludging of the red cells, marked rouleaux formation, an atypical Leishman stain, increased plasma viscosity, and a distorted protein electrophoresis pattern. The abnormal constituent was shown to be a mucopoly saccharide which was either hyaluronic acid or chondroitin sulphate.

Mucopolysaccharides normally occur in blood and urine only in low (less than $1 \mathrm{mg} / 100 \mathrm{ml}$ ) concentration (Manley, Severn, and Hawksworth, 1968). Their presence in the former is difficult to demonstrate unless special procedures requiring large volumes of blood are employed. However, large amounts can occur in body fluids in certain pathological states. Deutsch (1957) isolated hyaluronic acid from the serum of two patients, one with a neuroblastoma, and the other with a reticulum cell sarcoma. This substance has been found also in the body fluids of patients with mastocytosis (Asboe-Hanson and Clausen, 1964), mesotheliomata (Harington, Wagner, and Smith, 1963), metastatic adenocarcinoma (Meyer, Davidson, Linker, and Hoffman, 1956), and pseudomucinous cystadenomata (Jensen, 1954). Morse and Nussbaum (1967) reported the occurrence of hyaluronic acid in the blood and urine of a case of nephroblastoma which they investigated in considerable detail. This paper describes a case of neuroblastoma similar to that of Morse and Nussbaum (1967), with a mucopolysaccharide in the blood but not in the urine.

\section{Case Report}

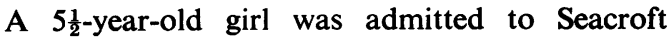
Hospital, Leeds, under the care of Dr M. F. G. Buchanan with a history of malaise for four months, vague, intermittent right hypochondria pain associated with anorexia and the passage of pale stools for two months, and abdominap swelling for one week.

On examination she was pale but not icteric $\overrightarrow{\vec{O}}$ with a pulse rate of $90 / \mathrm{min}$, and blood pressure of $125 / 100 \mathrm{~mm} \mathrm{Hg}$. The abdomen was obviously distended by a very large liver whose edge was smooth and firm. There was no abdomina $\overline{5}$ tenderness, ascites, splenomegaly, or enlarged kidneys and the cardiovascular and neurologica?. systems were normal. Examination of the respiro atory system suggested a pleural effusion ak the right lung base which was confirmed on chest radiographs. An intravenous pyelogram demonstrated the presence of a large abdominap mass lying posteriorly and mostly on the right side of the abdomen which was displacing the right kidney downwards and distorting its outline. The skull radiograph was normal.

Blood examination showed a haemoglobino level of $7.4 \mathrm{~g} / 100 \mathrm{ml}(100 \%$ value $=14.8 \mathrm{~g}$ $100 \mathrm{ml}$ ), WBC $11,400 \mathrm{cmm}$, ESR $40 \mathrm{~mm} / \mathrm{hr}$, with a normal platelet count and prothrombin time $\stackrel{\rho}{+}$ A direct Coombs test was negative. Bone marrow biopsy showed no adventitious cells. Routineurine tests, liver function tests, plasma urea, anç electrolyte levels were normal. Three 24-hou $\vec{D}$ urine specimens contained normal quantities of catecholamines and 3-methoxy-4-hydroxymandelic acid (HMMA). Laparotomy revealed a vase

Received for publication 1 July 1969. 


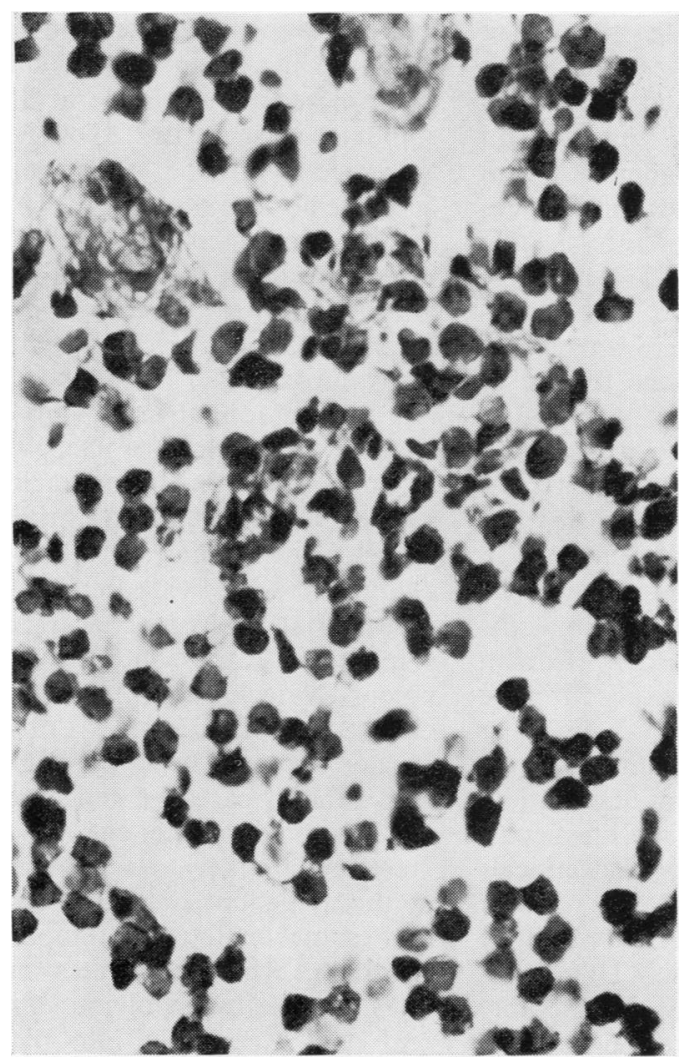

Fig. 1 Section of neuroblastoma showing a cellular tumour consisting of hyperchromic, ovoid cells some of which have small fibrillary processes projecting from the cell cytoplasm. $H \& E \times 600$.
A

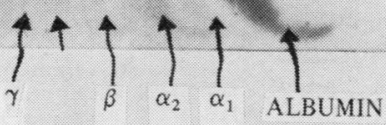

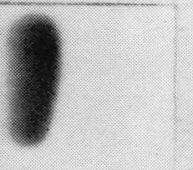

\section{Liver Biopsy Report}

The specimen consisted of soft, grey tissue measuring $1 \times 0.5 \times 0.2 \mathrm{~cm}$. Histologically both normal liver parenchyma and several coalescent micronodules of infiltrating tumour tissue were identified within the biopsy specimen. The tumour (Fig. 1), which was partly invested by a fibrous capsule, was highly cellular and was composed of masses of small, regular, ovoid cells with hyperchromic nuclei and scanty cytoplasm. The cells were arranged in groups supported by a vascular stroma, but there was no evidence of rosette formation and mitotic activity was not prominent. The appearances strongly suggested a neuroblastoma, and impregnation of the sections by Bodian and Bielschowsky's silver methods further supported this diagnosis by revealing small fibrillary processes projecting from the cell cytoplasm.

Sections stained by the periodic acid-Schiff and Alcian blue methods showed the presence of mucopolysaccharide material in the stromal elements only. In electron micrographs of the biopsy, large numbers of extracellular PASpositive granules were easily seen amongst cells in the area of the capsule of the growth. The biopsy having been fixed in formalin, it was unsuitable for histochemical tests using hyaluronidase or other enzymes.

The appearances were interpreted either as a blood-borne metastasis to the liver or direct invasion from a locally situated retroperitoneal or suprarenal primary tumour.

\section{Biochemical Investigations}

The presence of an abnormal blood constituent was suspected from the high ESR, sludging of the red cells in whole blood, marked rouleaux formation, and purple-staining homogeneous material in the background of a blood film stained by Leishman's method. No cryoglobulin or cryofibrinogen was detected and immunoelectrophoresis showed no abnormal protein bands or increase in immunoglobulins. Electrophoresis of serum proteins on cellulose acetate showed a marked concave bowing of the al-

Fig. 2 Electrophoresis of the patient's serum stained for protein. A, patient's serum untreated. B, normal serum untreated; $\mathrm{C}$, patient's serum pretreated with hyaluronidase. 
bumin, $\alpha_{1}, \alpha_{2}$, and $\beta$ globulin bands, suggesting that some factor in the serum was interfering with normal mobility and separation of proteins (Fig. 2). Urine, which contained $23 \mathrm{mg} / 100 \mathrm{ml}$ protein, was concentrated by Sephadex G25 and electrophoresis, then demonstrated only traces of albumin and globulins with no distortion of the bands and no atypical proteins. The heat test for Bence-Jones protein was negative.

Both serum and plasma were markedly viscous. The relative viscosity of the former at $37^{\circ} \mathrm{C}$ was 12.0 (normal $1 \cdot 5-1 \cdot 8$ ). The addition of 20 volumes of $3 \%$ acetic acid to plasma and to serum produced a voluminous white precipitate similar to that described in the nephroblastoma case of Morse and Nussbaum (1967), whereas normal plasma and serum and urine from the patient did not react. The Alcian blue test for excess mucopolysaccharides (Carson and Neill, 1962) gave a positive result with the patient's plasma and serum but not with her urine or with normal plasma and serum.

Blood, serum, and plasma from the patient were separately incubated at $37^{\circ} \mathrm{C}$ with testicular hyaluronidase (Hyalase, Fison's Pharmaceuticals Ltd.). The manufacturers state that this product splits hyaluronic acid and chondroitin sulphate but no other mucopolysaccharide. Thereafter, rouleaux formation in the blood was considerably diminished and the purple background material in a Leishman-stained film was much less. The test involving the addition of $3 \%$ acetic acid to serum was then negative and the Alcian blue reaction reduced but still present. The serum viscosity decreased to 1.76 and electrophoresis of both plasma and serum proteins showed a normal pattern with no evidence of the interference noted previously (Fig. 2). Staining of the latter electrophoresis strips with the periodicacid-Schiff reagent (Smith, 1968) demonstrated some increase in carbohydrate material migrating with the $\alpha_{2}$ globulin, which was not noted in the strips before incubation with hyaluronidase.

The hexuronic acid content of serum, determined by the non-specific method of Decker, McGuckin, McKenzie, and Slocumb (1959), was equivalent to approximately $75 \mathrm{mg}$ hyaluronic acid/100 $\mathrm{ml}$ serum. (The normal range equivalent to $4.4-7.5 \mathrm{mg}$ hyaluronic acid/100 $\mathrm{ml}$ serum was obtained from assay of 10 sera in our own laboratory.)

\section{Discussion}

In this case the findings of a high ESR, rouleaux formation, and an atypical Leishman stain, with increased plasma viscosity and distorted protein electrophoresis pattern, suggested the presence of an abnormal compound which was probably not a protein. The acetic acid and Alcian blue tests indicated that this was a carbo- hydrate derivative. The reversion of these find ings after incubation with hyaluronidase showef that either hyaluronic acid or chondroititi sulphate was present. Differentiation between these two compounds would depend on characte흠 izing the hexosamine.

Morse and Nussbaum (1967) in their case $\overrightarrow{\overline{0}}$ nephroblastoma reported similar haematologicad and chemical findings to our own. They found serum hexuronic acid concentrations equivalerf to hyaluronic acid levels of 163 and $272 \mathrm{mg} / 10 \mathrm{~g}$ $\mathrm{ml}$. In addition, their mucopolysaccharide con tained only glucosamine, the characteristic amino sugar of hyaluronic acid, and its infrare spectrum and carbon-to-nitrogen ratio obtained on elemental analysis were compatible wit hyaluronic acid. Evidence from spectroscopy suge gested that their mucopolysaccharide was noit sulphated. These authors also demonstrated mucopolysaccharide in the urine which was noto detected in our patient.

The source of the mucopolysaccharide in this and similar cases is not known. It was not demonstrated within the tumour cells and $\$$ therefore unlikely to be synthesized directl至. by the malignant cells. Deutsch (1957) suggeste that some malignant tumours produce hyat uronidase which infiltrates normal connective tissue, partially depolymerizing the hyaluronio acid and releasing it into the circulation. The electron micrograph findings were compatible with this theory.

The authors desire to thank Dr L. R. D. Tovey fo르 the haematological results, and Professor C. EO Lumsden for advice on the histology of the liver biopsy.

\section{References}

Asboe-Hanson, G., and Clausen, J. (1964). Urinary excretioß of acid mucopolysaccharides in 12 cases of mastocytosi

Carson, N. A. J., and Neill, D. W. (1962). Metabolic abnormalitie detected in a survey of mentally backward individuals in
Northern Ireland. Arch. Dis. Childh., 37, 505-513.

Decker, B., McGuckin, W. F., McKenzie, B. F., and Slocumb C. H. (1959). Concentration of hyaluronic acid in synoviab fluid. Clin. Chem., 5,465-469.
ch, H. F. (1957). Some properties of a human serunf Deutsch, H. F. (1957). Some properties of a human serunf
hyaluronic acid. J. biol. Chem., 224,767-774.

Harington, J. S., Wagner, J. C., and Smith, M. (1963). The detection of hyaluronic acid in pleural fluids of cases with diffuse pleural mesotheliomas. Brit. J. exp. Path., $44 \Phi$

Jensen, C. E. (1954). Hyaluronic acid. IV. Isolation of hyaluronic
acid from pseudomucinous ovarian cysts. Acta pharmacol acid from pseudomucinous ovarian cysts. Acta pharmacolo
$(K b h), 10,.83-88$.

Meyer, K., Davidson, E., Linker, A., and Hoffman, P. (1956)吕 The acid mucopolysaccharides of connective tissue?
Biochim. biophys. Acta (Amst.), 21, 506-518.

Manley, G., Severn, M., and Hawksworth, J. (1968). Excretior patterns of glycosaminoglycans and glycoproteins in

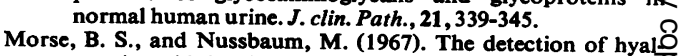
uronic acid in the serum and urine of a patient witk nephroblastoma. Amer. J. Med., 42,996-1002.

Smith, I. (1968). Chromatographic and Electrophoretic Technique $\overline{\mathrm{Q}}$ 2nd ed., Vol. 2, Zone Electrophoresis. Heinemann, London? 